
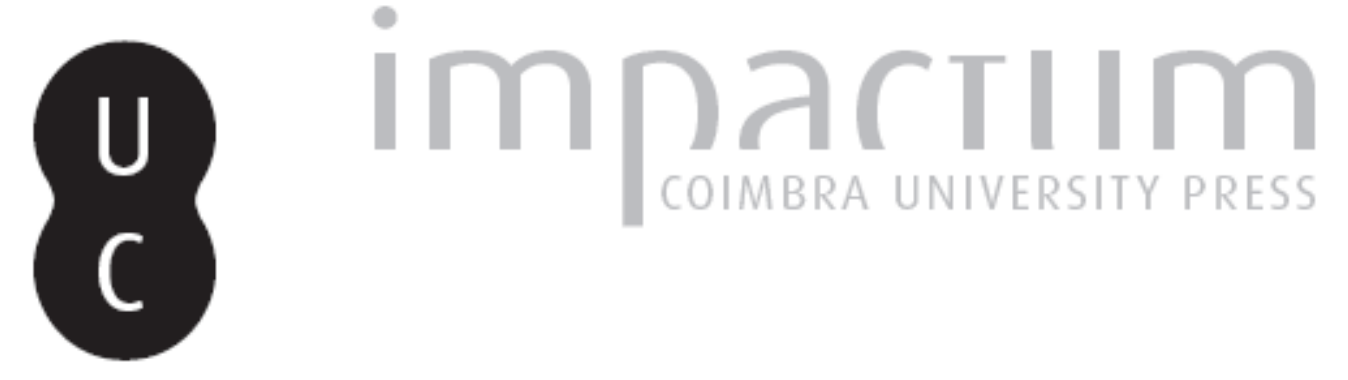

Risco de fadiga em ambiente térmico frio: caso de uma indústria de peixe congelado Autor(es): $\quad$ Talaia, Mário; Teixeira, Leonor; Tavares, Isabel

Publicado por: Imprensa da Universidade de Coimbra

URL persistente:

URI:http://hdl.handle.net/10316.2/43275

DOI:

DOI:https://doi.org/10.14195/1647-7723_25-1_8

Accessed : $\quad$ 26-Apr-2023 12:40:48

A navegação consulta e descarregamento dos títulos inseridos nas Bibliotecas Digitais UC Digitalis, UC Pombalina e UC Impactum, pressupõem a aceitação plena e sem reservas dos Termos e Condições de Uso destas Bibliotecas Digitais, disponíveis em https://digitalis.uc.pt/pt-pt/termos.

Conforme exposto nos referidos Termos e Condições de Uso, o descarregamento de títulos de acesso restrito requer uma licença válida de autorização devendo o utilizador aceder ao(s) documento(s) a partir de um endereço de IP da instituição detentora da supramencionada licença.

Ao utilizador é apenas permitido o descarregamento para uso pessoal, pelo que o emprego do(s) título(s) descarregado(s) para outro fim, designadamente comercial, carece de autorização do respetivo autor ou editor da obra.

Na medida em que todas as obras da UC Digitalis se encontram protegidas pelo Código do Direito de Autor e Direitos Conexos e demais legislação aplicável, toda a cópia, parcial ou total, deste documento, nos casos em que é legalmente admitida, deverá conter ou fazer-se acompanhar por este aviso. 
territorium/25w|.

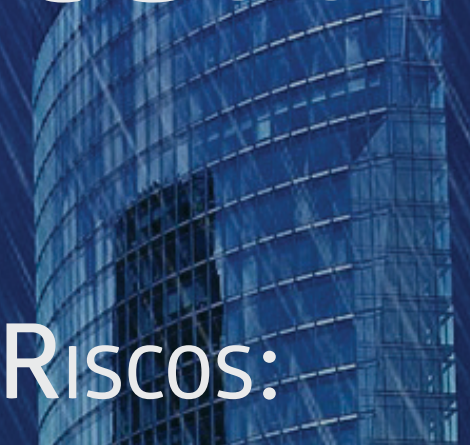

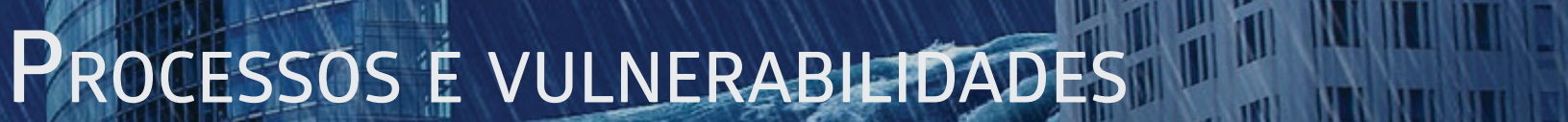

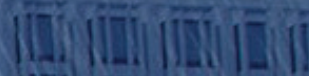
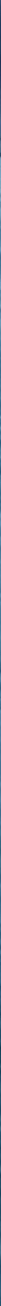

Imprensa da Universidade de Coimbra

Associação Portuguesa de Riscos, Prevenção e Segurança

2018 


\section{RISCO DE FADIGA EM AMBIENTE TÉRMICO FRIO: CASO DE UMA INDÚSTRIA DE PEIXE CONGELADO*}

RISK OF FATIGUE IN COLD THERMAL ENVIRONMENT: THE CASE OF THE QUICK-FROZEN FISH INDUSTRY

Mário Talaia

Departamento de Física da Universidade de Aveiro (Portugal) mart@ua.pt

Leonor Teixeira

Departamento de Economia, Gestão e Engenharia Industrial da Universidade de Aveiro (Portugal) tteixeira@ua.pt

Isabel Tavares

Departamento de Economia, Gestão e Engenharia Industrial da Universidade de Aveiro (Portugal) isabel.tavares@ua.pt

\section{RESUMO}

Em diferentes indústrias caraterizadas com ambientes quentes, confortáveis e/ou frios, os trabalhadores devem usar um vestuário em função da atividade desenvolvida. 0 ambiente térmico desempenha um papel muito importante no melhoramento das condições de trabalho, com impacto direto na produtividade do trabalhador. As caraterísticas termohigrométricas de um ambiente térmico podem afetar o bem-estar, a fadiga e a produtividade do trabalhador. Neste trabalho é avaliada uma secção de embalamento de peixe demolhado ultracongelado, considerado um ambiente térmico frio. Foram registados valores da temperatura e humidade relativa do ar, e da sensação térmica real do trabalhador, numa escala de cores. Os resultados obtidos mostram que o padrão de sensação térmica depende do tipo de embalamento, que influencia a sensação térmica dos trabalhadores.

Palavras-chave: Ambiente térmico frio, sensação térmica, índice EsConTer, ITH, PPD.

\section{ABSTRACT}

In industries characterized with different environment conditions, as warm, comfortable and/or cool environments workers clothing should be appropriate for their specific activity. The thermal environment plays an important role in improving working conditions, with a direct impact on worker productivity. The thermohygrometric characteristics of a thermal environment can affect the well-being, fatigue and productivity of workers. In this study the quick-frozen fish section, considered a cold thermal environment, is evaluated. The values of temperature and relative humidity, as well as the real thermal sensation of the worker were collected in a colour scale. The results show that the pattern of thermal sensation depends on the type of packaging which influences the thermal sensation of workers.

Keywords: Cold thermal environment, thermal sensation, EsConTer index, THI, PPD.

Keywords: Cold thermal environment, thermal sensation, EsConTer index, THI, PPD.

\footnotetext{
* O texto deste artigo foi submetido em 13-06-2016, sujeito a revisão por pares a 15-09-2016 e aceite para publicação em 24-04-2017.

Este artigo é parte integrante da Revista Territorium, n. ${ }^{\circ} 25$ (I), 2018, ${ }^{\circ}$ RIscos, ISSN: 0872-8941.
} 
Introdução

A ergonomia tem um vasto campo de atuação desde o conforto/desconforto físico passando pelos processos mentais até aos processos ambientais, sendo igualmente importante na definição de tarefas para que estas sejam eficazes e tenham em conta as necessidades humanas.

O ambiente térmico pode ser designado como o conjunto de variáveis térmicas que influenciam as trocas de calor entre o ser humano e o meio ambiente envolvente. Dentro do âmbito da arquitetura foi criada legislação de conforto térmico que considera o conforto térmico como "a satisfação expressa quando um indivíduo é sujeito a um determinado ambiente térmico" (ISO 7730, 2005).

O organismo humano utiliza vários mecanismos para promover o balanço térmico. Durante o ambiente térmico frio o organismo pode acelerar o metabolismo para produzir mais energia sob a forma de calor. Neste contexto ambiental o vestuário também ajuda a manter a temperatura corporal. De notar que a sensação térmica é subjetiva, isto é, depende de cada pessoa, sendo que um determinado ambiente pode ser termicamente confortável para uma pessoa e ser frio ou quente para outra.

Um ambiente térmico é considerado frio quando o organismo de uma pessoa tem necessidade de desencadear mecanismos de luta contra o frio. A hipotermia que constitui a patologia geral devida ao frio por falência da termoregulação traduz-se no início por um arrepio generalizado, uma temperatura interna que diminui e uma pressão arterial que aumenta. Os movimentos dos dedos e das mãos podem também sofrer uma deterioração apreciável, mesmo com níveis moderados de exposição. As frieiras, a diminuição da destreza manual e a redução da sensibilidade são elementos a valorizar. Uma temperatura registada nas mãos abaixo dos $8^{\circ} \mathrm{C}$ provoca uma diminuição da sensibilidade tátil e entre $12^{\circ} \mathrm{C}$ e $16^{\circ} \mathrm{C}$ uma diminuição para a destreza manual (Parsons, 1993). Stoops (2004) mostrou que o controlo individual de sistemas de climatização, dependendo da atividade desenvolvida, proporciona um aumento da produtividade.

\section{Ambiente térmico e conforto térmico}

O ambiente térmico pode ser designado como o conjunto das variáveis térmicas que influenciam as trocas de calor entre o ser humano e o meio onde este se insere, desempenhando um papel importante na melhoria das condições de trabalho, bem como na qualidade de vida (Miguel, 2012). De acordo com a ASHRAE (American Society of Heating, Refrigerating and Air-Conditioning Engineers), o conforto térmico pode ser definido como "o estado de espírito em que o indivíduo expressa satisfação em relação ao ambiente térmico" (ISO 7730,
2005; ASHRAE, 2004). Mas esta definição implica um certo grau de subjetividade e pressupõe a análise de dois aspetos: aspetos físicos (ambiente térmico) e aspetos subjetivos (estado de espírito do indivíduo).

A satisfação de todos os indivíduos inseridos num ambiente térmico é uma tarefa "quase" impossível pois um ambiente termicamente confortável para uma pessoa pode ser desconfortável para outra. Logo, o ideal seria a criação de um ambiente térmico que satisfaça o maior número de pessoas. De acordo com a norma ISO 7730 (2005), o desconforto térmico pode ser causado por um ambiente térmico frio ou quente e por um desconforto térmico localizado numa parte específica do corpo. Este desconforto pode causar uma redução significativa do desempenho. O conforto térmico é obtido quando um indivíduo está numa condição de equilíbrio com o ambiente que o rodeia (temperatura do corpo humano aproximadamente constante, próxima de $37,0^{\circ} \mathrm{C} \pm 0,8^{\circ} \mathrm{C}$ ), o que significa que é possível a manutenção da temperatura dos tecidos constituintes do corpo, num domínio de variação estrito, sem que haja esforço adicional. Esta é a situação ideal que corresponde a um ambiente neutro ou confortável. Fora deste ambiente pode haver alterações fisiológicas no ser humano. É necessário assegurar que os trabalhadores não se deparam com situações de desconforto térmico uma vez que daqui resultam riscos desnecessários (Costa, Baptista, Diogo e Magalhães, 2011).

Ambientes térmicos frios podem desencadear reações físicas e psicológicas em qualquer ser humano. No entanto, ainda existem muitas contradições e falhas no que se refere a explicações concretas sobre as consequências do desconforto térmico na fadiga e produtividade (Tavares, 2015). Na verdade, o constante esforço por um ambiente de trabalho saudável e trabalhadores saudáveis é um pré-requisito para a inovação e produtividade numa economia baseada no conhecimento, ganhando cada vez mais espaço nas empresas (Dias, 2013).

$\mathrm{Na}$ TABela I são apresentados efeitos fisiológicos e psicológicos para diferentes durações de exposição a stress térmico por frio.

O stress térmico por frio pode estar presente de muitas formas diferentes, afetando o equilíbrio térmico de todo o corpo, assim como o equilíbrio térmico das extremidades, a pele e os pulmões. 0 arrefecimento de todo o corpo ou de algumas partes do mesmo origina doenças, insensibilidade, função neuromuscular reduzida e em última instância lesões por frio. Na TABELA II podem ser verificados alguns efeitos esperados da exposição leve e intensa ao frio.

No presente estudo pretende-se analisar o padrão da sensação térmica de uma secção de embalamento de peixe demolhado ultracongelado, conhecer a localização de postos de trabalho mais vulneráveis a stress térmico, 
TABELA I -Stress por frio e reações associadas.

TABLE I - Stress from cold and associated reactions.

\begin{tabular}{|c|c|c|}
\hline Duração & Efeitos fisiológicos & Efeitos psicológicos \\
\hline \multirow{5}{*}{ Segundos } & Respiração ofegante & \multirow{5}{*}{$\begin{array}{c}\text { Sensação cutânea, } \\
\text { Desconforto }\end{array}$} \\
\hline & Hiperventilação & \\
\hline & Aumento da frequência cardíaca & \\
\hline & Vasoconstrição periférica & \\
\hline & Aumento da pressão arterial & \\
\hline \multirow{5}{*}{ Minutos } & Arrefecimento dos tecidos & \multirow{5}{*}{$\begin{array}{c}\text { Redução do rendimento } \\
\text { Dor por arrefecimento local }\end{array}$} \\
\hline & Arrefecimento das extremidades & \\
\hline & Deterioração neuromuscular & \\
\hline & Tremores & \\
\hline & Arrefecimento por contacto e convecção & \\
\hline \multirow{3}{*}{ Horas } & Menor capacidade para o trabalho físico & \multirow{3}{*}{ Deterioração da função mental } \\
\hline & Hipotermia & \\
\hline & Lesões por frio & \\
\hline \multirow{2}{*}{ Dias/ Meses } & Lesões por frio sem congelamento & Hábito \\
\hline & Aclimatização & Pequenas irritações/doenças \\
\hline Anos & Efeitos crónicos nos tecidos & \\
\hline
\end{tabular}

Fonte: Holmér, Granberg e Dahlstrom, 1999. Source: Holmér, Granberg e Dahlstrom, 1999.

TABELA II - Efeitos ao frio.

TABLE II - Effects of the cold.

\begin{tabular}{|l|c|c|}
\hline \multicolumn{1}{|c|}{ Rendimento } & $\begin{array}{c}\text { Exposição } \\
\text { leve ao } \\
\text { frio }\end{array}$ & $\begin{array}{c}\text { Exposição } \\
\text { intensa ao } \\
\text { frio }\end{array}$ \\
\hline Rendimento manual & $0 \pm$ & \pm \pm \\
\hline Rendimento muscular & 0 & \pm \\
\hline Rendimento aeróbico & 0 & \pm \\
\hline Tempo de reação simples & 0 & \pm \\
\hline Tempo de reação consciente & \pm & \pm \\
\hline Observação, vigilância & $0 \pm$ & \pm \pm \\
\hline Tarefas cognitivas, mentais & $0 \pm$ & \pm \\
\hline $\begin{array}{l}0 \rightarrow \text { nenhum efeito; } \pm \rightarrow \text { deterioração; } \pm \pm \rightarrow \text { deterioração grave; } \\
0 \pm \rightarrow \text { observações contraditórias }\end{array}$ \\
\hline
\end{tabular}

Fonte/Source: Holmér et al., 1999.

conhecer a sensação térmica real dos trabalhadores, identificar as zonas do corpo com maior desconforto e, ainda, identificar medidas de intervenção para a melhoria da fadiga e bem-estar do trabalhador.

\section{Materiais e métodos}

Existem três contextos que definem a performance de um ambiente térmico: o "clima" do espaço, a atividade desempenhada pelos trabalhadores e o próprio edifício que define o espaço. Considerando estes pressupostos, determinou-se o padrão de sensação térmica na secção de embalamento de peixe demolhado ultracongelado de uma empresa de transformação de peixe. Esta secção é considerada de ambiente frio e tem formato retangular com uma área de cerca de $230 \mathrm{~m}^{2}$, que é mostrada na fig. 1, com uma linha de cor verde onde estão localizados 19 dos 26 postos de observação e registo de variáveis termohigrométricas. Foram usados postos de observação fora da área de estudo e retangular com linha a cor verde, do P20 ao P26, com o objetivo de serem controlados os mapas de cores pela influência direta dos valores termohigrométricos registados junto à fronteira.

Neste estudo são usadas duas abordagens de recolha e tratamento de dados: (i), uma de carácter objetivo, com a recolha de dados termohigrométricos, sendo a identificação do padrão de sensação térmica feito através da aplicação de índices de conforto térmico; (ii) outra de carácter subjetivo, através da aplicação de uma escala de cores aos trabalhadores, com o objetivo de conhecer a sensação térmica real do trabalhador e onde estes indicavam as zonas do corpo com sensação de stress ao frio.

Identificados os pontos de observação em número de 26 definiu-se o trajeto de observação. Foram inicialmente testados dois circuitos, sendo o primeiro iniciado no posto de observação P22 e finalizado no posto P25 e o segundo iniciado no posto P25 e finalizado no posto P22 (fig.1). A realização destes dois circuitos prende-se com a necessidade de perceber a variação do ambiente térmico da secção em estudo durante o período de tempo de registo de dados, o que se concluiu ser coerente e conduzir ao mesmo padrão. Em cada ponto de observação foram registados os valores da temperatura do ar e humidade relativa do ar, usando para o efeito o instrumento de medida "Center 317 - temperature humidity center".

Os 17 trabalhadores da secção em estudo são todos do sexo feminino, com uma idade $37 \pm 12$ anos, uma massa corporal de $64 \pm 12 \mathrm{~kg}$ e uma altura de $159 \pm 9 \mathrm{~cm}$. 


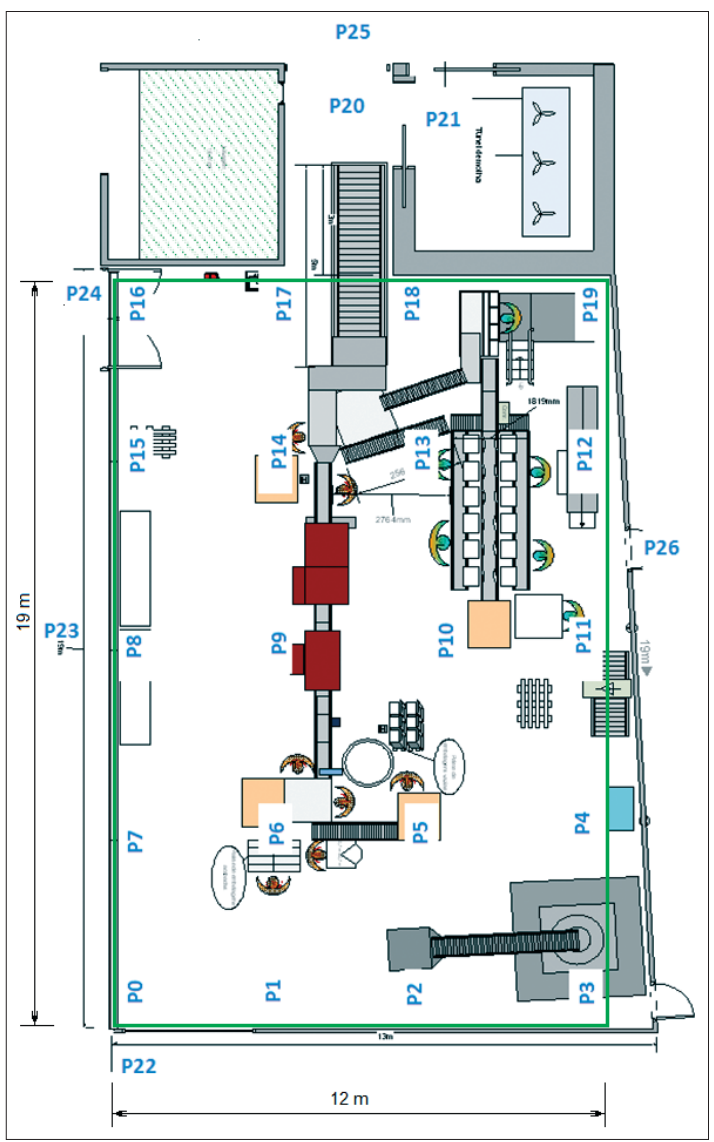

Fig. 1 - Layout da secção com identificação dos pontos de observação

Fig. 1 - Layout of section with identification of observation points.

A perceção dos trabalhadores foi avaliada através da aplicação de uma escala sétima de cores, no posto de trabalho e foram registadas informações acerca de zonas do corpo onde os trabalhadores sentiam maior desconforto. Os dados foram registados entre os meses de Janeiro e Março, e em diferentes tipos de embalamento:

Embalamento A - Embalamento (caixas de $1 \mathrm{~kg}$ ) sem descarga de peixe;

Embalamento B - Embalamento (caixas de $1 \mathrm{~kg}$ ) com descarga de peixe;

Embalamento C - Embalamento (caixas de 6,5kg) de peixe posta longa;

Embalamento D - Embalamento (caixas de 6,5kg) de peixe posta média.

Através de um algoritmo construído em MatLab, foram gerados mapas de cores de humidade relativa do ar, índice ITH, índice EsConTer e índice PPD, que teve como finalidade avaliar o conforto/desconforto térmico nos postos de trabalho operacionais, em cada tipo de embalamento.

O índice ITH (índice de temperatura e humidade), modificado por Nieuwolt (1977) usa a temperatura e a humidade relativa do ar e é calculado a partir da expressão:
$\mathrm{ITH}=0.75 \mathrm{~T}+\mathrm{T}(\mathrm{HR} / 500)$

em que $\mathrm{T}$ representa a temperatura do $\operatorname{ar}\left({ }^{\circ} \mathrm{C}\right)$ e $\mathrm{HR}$ a humidade relativa do ar (\%).

$\mathrm{Na}$ TABELA III são indicados os valores de referência adaptados por Talaia, Meles e Teixeira (2013) para uma vasta gama de valores de ITH, com base nas estratégias descritas no diagrama da Organização Mundial de Meteorologia (WMO, 1987).

TABELA III - Valores para o ITH.

TABLE III - Typical values of the THI.

\begin{tabular}{|c|l|}
\hline ITH $\left({ }^{\circ} \mathrm{C}\right)$ & \multicolumn{1}{c|}{ Sensação térmica } \\
\hline ITH $<8$ & $\begin{array}{l}\text { Demasiado frio (100\% dos indivíduos } \\
\text { estão desconfortáveis) }\end{array}$ \\
\hline $8 \leq \mathrm{ITH}<21$ & $\begin{array}{l}\text { Necessidade de aquecimento (50\% dos } \\
\text { indivíduos estão desconfortáveis) }\end{array}$ \\
\hline $21 \leq \mathrm{ITH}<24$ & $\begin{array}{l}\text { Confortável (100\% dos indivíduos estão } \\
\text { confortáveis) }\end{array}$ \\
\hline $24 \leq \mathrm{ITH}<26$ & $\begin{array}{l}\text { Necessidade de ventilação (50\% dos } \\
\text { indivíduos estão confortáveis) }\end{array}$ \\
\hline $26 \leq \mathrm{ITH}$ & $\begin{array}{l}\text { Demasiado quente (100\% dos indivíduos } \\
\text { estão desconfortáveis) }\end{array}$ \\
\hline
\end{tabular}

Fonte/Source: Talaia et al., 2013.

Foi também usado o índice EsConTer (Talaia e Simões, 2009; Morgado, Talaia e Teixeira, 2015) baseado numa escala de cores (Es), por considerar a sensação de conforto (Con) e por ser térmica (Ter) e é calculado aplicando a expressão,

$$
\text { EsConTer }=-3,75+0,103\left(T+T_{w}\right)
$$

onde $\mathrm{T}$ representa a temperatura do $\operatorname{ar}\left({ }^{\circ} \mathrm{C}\right)$ e $\mathrm{T}_{w}$ a temperatura do termómetro húmido $\left({ }^{\circ} \mathrm{C}\right)$.

0 índice EsConTer na gama de valores $-3 a+3$ permite mostrar a sensação térmica de um ambiente de muito frio a muito quente. Numa escala de cores construída para o efeito (fig. 2), os trabalhadores são convidados a expressarem a sua sensação térmica (Talaia e Rodrigues, 2008), ou seja, estes devem marcar uma "cruz" na sensação térmica que estão a sentir no momento da observação. A grande vantagem deste índice é a facilidade de leitura e interpretação da escala usada de $-3 a+3$.

Foi ainda aplicado o índice PPD, cujo valor nunca inferior é a $5 \%$, que estabelece a percentagem de pessoas termicamente insatisfeitas com o ambiente e é determinado a partir do conhecimento do índice PMV (ISO 7730, 2005). Como o índice EsConTer usa a gama de valores de $-3 \mathrm{a}+3$ para mostrar a sensação térmica de um ambiente, de muito frio a muito quente, equivalente à escala sétima de sensação térmica da ASHRAE (ASHRAE, 2004), na expressão do PPD o índice PMV foi substituído pelo índice EsConTer,

PPD $=100-95^{*} \exp \left[-\left(0,03353^{*} E^{2} C_{0 n T e r}{ }^{4}+0,2179 * E^{*} C_{0 n T e r}{ }^{2}\right)\right]$ 


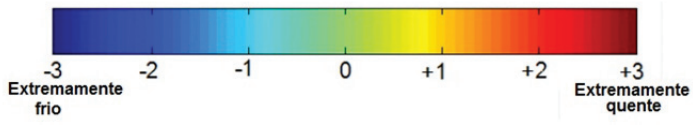

Fig. 2 - Escala térmica de cores.

Fig. 2 - Thermal sensation scale.

\section{Resultados e discussão}

Foi usado um algoritmo em MatLab que permitiu traçar mapas de cores com o intuito de analisar o ambiente térmico da secção. Com os valores da temperatura do ar e da humidade relativa do ar, tendo em conta as diferentes situações de embalamento, foram traçados mapas de cores relativos à humidade relativa do ar e aos índices ITH, EsConTer e PPD.

Os eixos das ordenadas e das abcissas representam o comprimento e a largura da área de estudo ou seja da secção de embalamento. No lado direito de cada gráfico está indicada uma escala de cores que está associada aos valores da variável estudada. Para cada situação as escalas foram normalizadas de modo a facilitar a interpretação do padrão de cor e das linhas indicadas.

A fig. 3 mostra os padrões obtidos para os índices EsConTer, ITH, PPD e para a humidade relativa do ar numa situação de embalamento sem descarga de peixe (Embalamento A - embalamento de caixas de $1 \mathrm{~kg}$ ).

A observação da fig. 3 mostra, tendo por base os resultados obtidos do padrão para o índice EsConTer e ITH, que a sensação térmica prevista na secção é de ligeiramente fria a fria. Há postos de trabalho na zona de frio, nomeadamente o caso dos trabalhadores A, B e G. Estes postos de trabalho estão sujeitos a stress térmico frio e deverão usar roupa de proteção adequada. Os resultados mostram que se prevê através do índice PPD insatisfação de $55 \%$ a $70 \%$ dos trabalhadores localizados na zona mais vulnerável a stress térmico ao frio. A observação da figura mostra que os índices EsConTer e ITH identificam os mesmos postos de trabalho em termos de maior vulnerabilidade ao frio. 0 padrão da humidade relativa do ar mostra que a zona de maior vulnerabilidade regista valores entre cerca de 65 a $75 \%$.

A fig. 4 mostra os padrões obtidos para os índices EsConTer, ITH, PPD e para a humidade relativa do ar numa situação de embalamento com descarga de peixe (Embalamento B - Embalamento de caixas de $1 \mathrm{~kg}$ ).

No embalamento $B$ há descarga de peixe e este chega à máquina da linha de produção a uma temperatura muito negativa o que faz registar uma temperatura do ar entre $9,0^{\circ} \mathrm{C}$ e $10,6^{\circ} \mathrm{C}$, para a área de estudo. A zona mais vulnerável a stress térmico inclui os trabalhadores $A, B$, C, D, E e G. A insatisfação atinge valores de cerca de
$75 \%$ o que para o Departamento de Higiene e Segurança é um alerta de que os trabalhadores devem estar com vestuário adequado para não afetarem a destreza no manuseamento do peixe congelado.

A observação da fig. 4 mostra que a sensação térmica prevista na secção é de fria a muito fria. Nesta situação o índice EsConTer mostra que se prevê uma sensação térmica de $-1,9$ a $-2,0$ o que indica que para o trabalhador continuar a trabalhar sem fadiga e sem entrar em hipotermia deve estar devidamente protegido em termos de vestuário. Os valores previstos com a aplicação do índice EsConTer estão em concordância com os valores previstos por aplicação do índice ITH. Este índice mostra que para os valores obtidos há necessidade de aquecimento, ou seja cerca de $50 \%$ dos trabalhadores estão desconfortáveis no posto de trabalho. No limite inferior deste índice e com um valor de $8^{\circ} \mathrm{C}$ é previsto que $100 \%$ dos trabalhadores estejam insatisfeitos. A resolução de conforto térmico para este tipo de atividade, como é natural, não pode ser realizada através de aquecimento.

A solução deve passar por estratégias de diminuição da humidade relativa do ar, uso de vestuário adequado e por rotação do trabalhador (após ser determinado o tempo de segurança para se manter a destreza sem qualquer tipo de limitação).

A fig. 5 mostra os padrões obtidos para os índices EsConTer, ITH, PPD e para a humidade relativa do ar numa situação de embalamento de peixe posta longa (Embalamento C - Embalamento de caixas de 6,5kg).

A observação da fig. 5 revela que a sensação térmica prevista na secção é de ligeiramente fria. Neste caso, sendo um ambiente térmico ligeiramente frio, parece sugerir que o posto de trabalho $M$ seja considerado o mais vulnerável, com um valor previsto de cerca de -1,3 para o índice EsConTer e uma previsão de insatisfação do trabalhador de cerca de $40 \%$. Este embalamento regista uma temperatura do ar mais alta, entre $12,8^{\circ} \mathrm{C}$ a $13,7^{\circ} \mathrm{C}$ devido a existência de uma máquina que tem um forno o que pode influenciar o ambiente térmico e consequentemente a sensação térmica dos trabalhadores com os seus postos de trabalho aí localizados. Neste tipo de embalamento a humidade relativa do ar regista valores entre cerca de $70 \%$ a $78 \%$.

A fig. 6 mostra os padrões obtidos para os índices EsConTer, ITH, PPD e para a humidade relativa do ar numa situação de embalamento de peixe posta média (Embalamento D - Embalamento de caixas de 6,5kg).

Na fig. 6 são mostrados os padrões para uma situação de embalamento $\mathrm{D}$. Neste embalamento a temperatura do ar situa-se entre $10^{\circ} \mathrm{C}$ e $12^{\circ} \mathrm{C}$. Os trabalhadores encontramse numa sensação térmica de frio (cerca de -1,6 a -1,9) e o índice PPD prevê que cerca de 70\% dos trabalhadores estarão insatisfeitos se não usarem vestuário adequado 

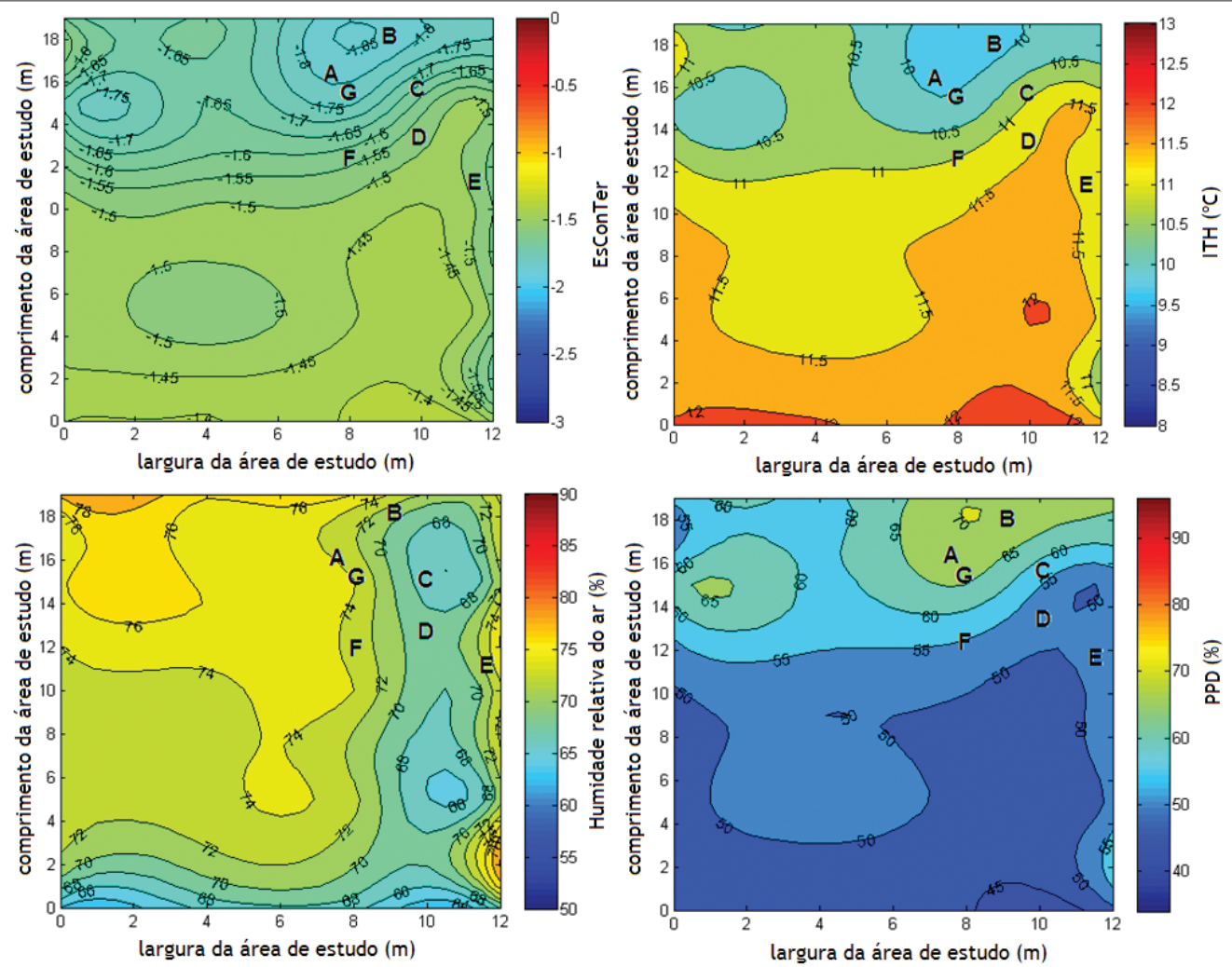

Fig. 3 - Embalamento A.

Fig. 3 - Packaging A.
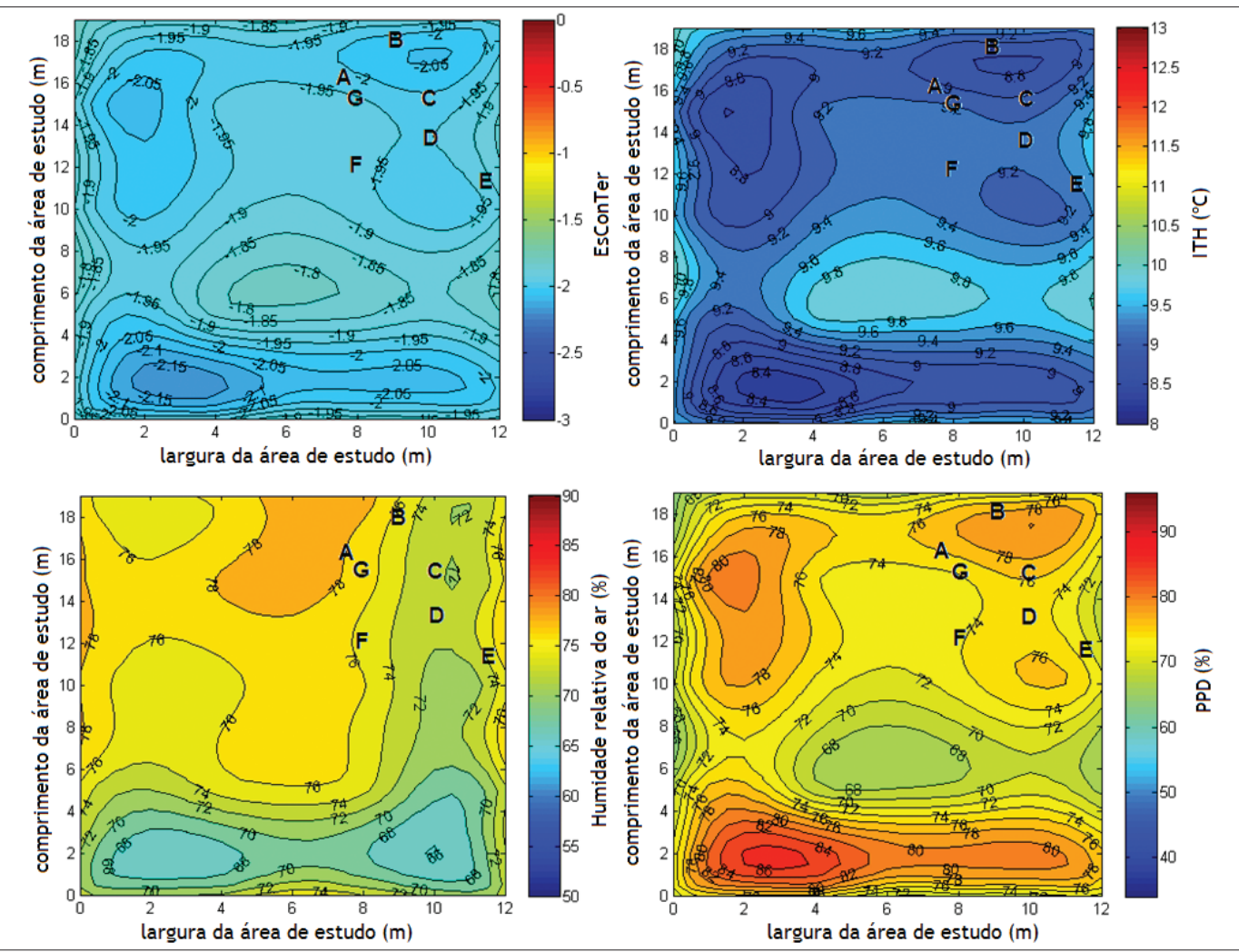

Fig. 4 - Embalamento $B$

Fig. 4 - Packaging $B$. 


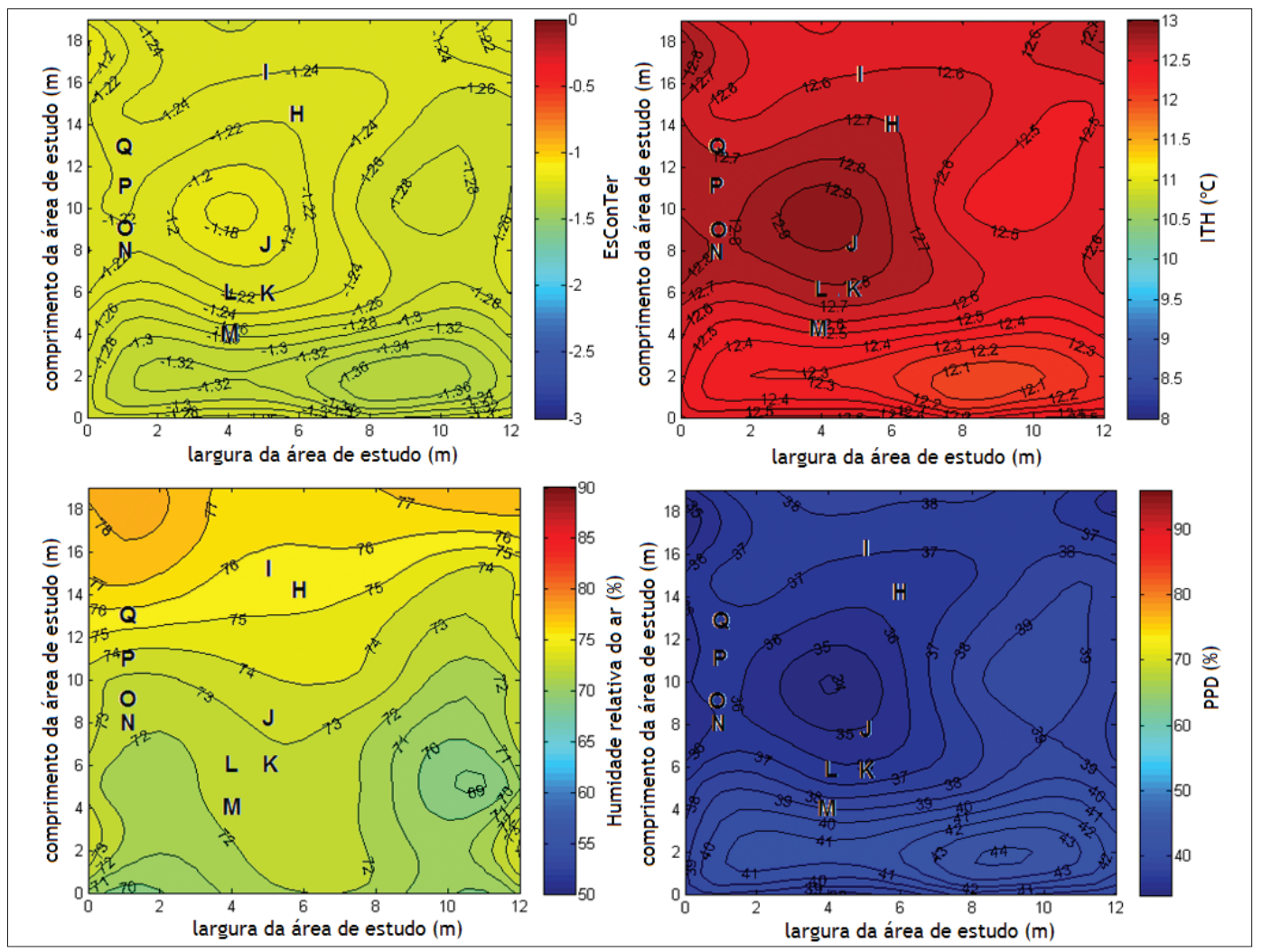

Fig. 5 - Embalamento $\mathrm{C}$.

Fig. 5 - Packaging C.
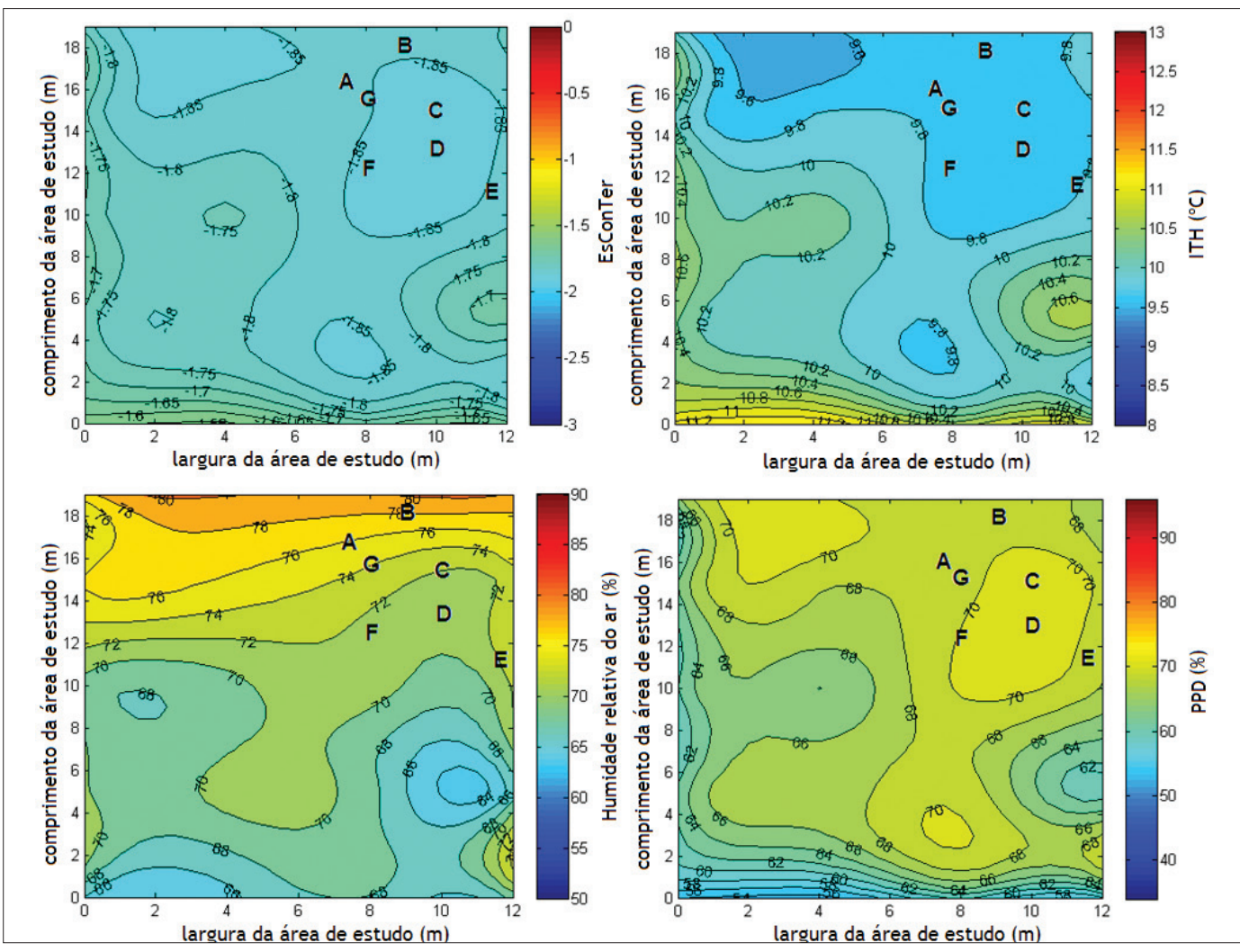

Fig. 6 - Embalamento D.

Fig. 6 - Packaging D. 
de proteção. A observação do padrão do EsConTer e do ITH mostra, mais uma vez uma excelente correlação.

Pode-se concluir que abordando as diferentes situações de embalamento o índice EsConTer é um excelente preditor para se conhecer a sensação térmica de um espaço, com a vantagem face ao ITH por prescindir de consulta de tabelas.

Relativamente aos índices EsConTer e ITH, comprova-se a concordância das suas interpretações, sugerindo que mesmo em diferentes tipos de embalamento, estes índices comportam-se da mesma maneira, oferecendo as mesmas sugestões para aplicação de estratégias de intervenção. $O$ índice EsConTer por considerar a escala da ASHRAE é de fácil e imediata interpretação e deve ser valorizado em contexto de ambiente frio (Morgado et al., 2015).

No geral a secção estudada é de ambiente térmico frio, no entanto os postos de trabalho que foram considerados como vulneráveis, para cada tipo de embalamento, podem e devem exigir uma maior atenção por parte da Direção da Qualidade que é responsável também pela Higiene e Segurança.

Para além da avaliação do padrão da sensação térmica da secção através de índices térmicos, nos 17 postos de trabalho, foi também efetuada a avaliação da sensação térmica real do trabalhador, através da aplicação de uma escala sétima de cores (ver fig. 2). Através do preenchimento da escala de cores que foi aplicada aos trabalhadores, foi obtida a sensação térmica, ou seja, o que os trabalhadores diziam sentir quanto ao ambiente térmico em seu redor. 0 índice EsConTer que prevê a sensação térmica a partir das variáveis ambientais, temperatura do ar e humidade relativa, foi utilizado para comparar a sensação térmica prevista com a sensação térmica real sentida pelos trabalhadores.

Na fig. 7 é apresentado o gráfico que mostra a relação entre a sensação térmica real indicada pelos trabalhadores e a sensação térmica prevista pelo índice EsConTer.

$\mathrm{Na}$ fig. 7 os círculos a negrito representam os dados observados ou seja a sensação térmica do operador ou trabalhador face a sensação térmica prevista por aplicação do índice EsConTer. A linha a verde representa a tendência para valores previstos face aos dados observados e a linha a negrito os valores previstos face ao índice EsConTer.

A observação da fig. 7 mostra que a sensação térmica real dos trabalhadores segue a previsão da sensação térmica indicada pelo índice EsConTer. À medida que o valor da sensação térmica indicia um ambiente térmico muito frio há um desvio absoluto da sensação térmica real do trabalhador em face do previsto, como se pode verificar pela linha a cor verde que se desvia da linha teórica a negrito. Este desvio está ligado ao tipo de atividade desenvolvido pelo trabalhador e ao vestuário usado (ISO 7730, 2005).

As sensações térmicas relatadas pelos trabalhadores são quase todas explicadas pelo índice EsConTer o que indicia uma boa precisão. Há uma relação significativa entre as sensações térmicas previstas e as sensações térmicas reais, o que denota um bom ajuste do modelo EsConTer. Assim, o gráfico da fig. 7 mostra como o índice EsConTer é um bom preditor da sensação térmica indicada pelos trabalhadores.

Os trabalhadores para o tipo de embalamento A, B e $D$ registaram uma sensação real de $-1,35 \pm 0,08$ face a uma sensação prevista pelo índice EsConTer de $-1,82 \pm$

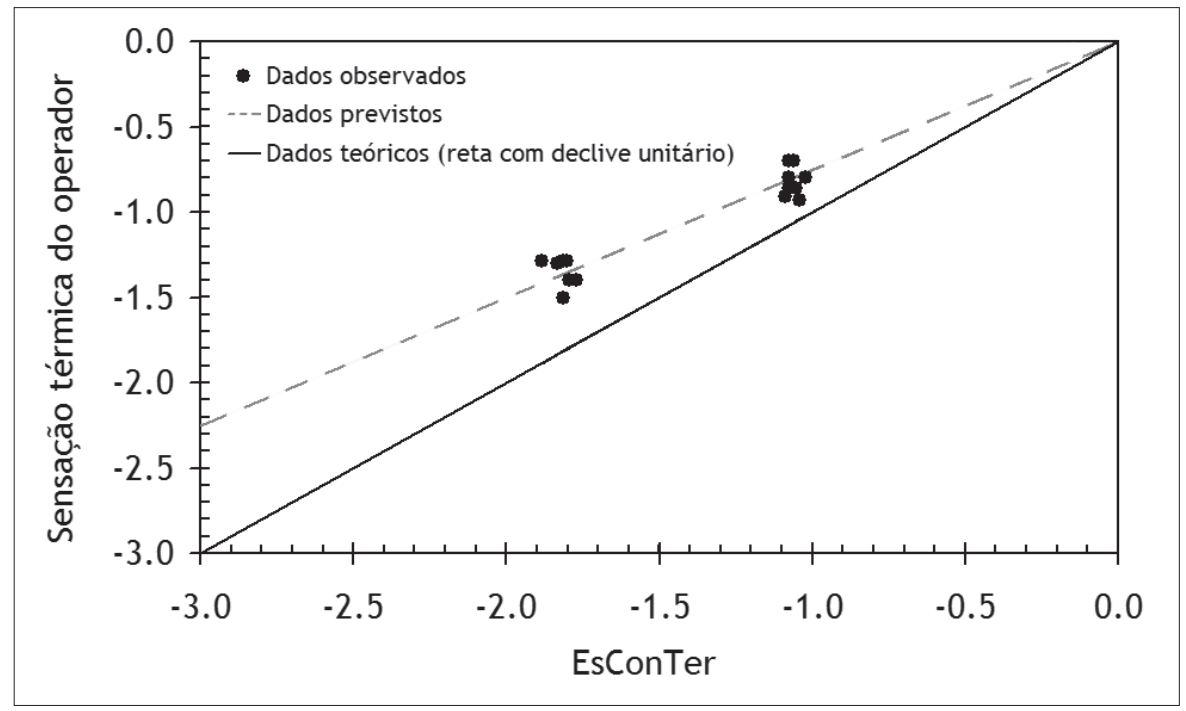

Fig. 7 - Sensação térmica real versus sensação térmica prevista.

Fig. 7 - Real thermal sensation versus estimated thermal sensation. 
0,04 . Os trabalhadores para o tipo de embalamento $C$ registaram uma sensação real de $-0,82 \pm 0,08$ face a uma sensação prevista pelo índice EsConTer de -1,06 \pm 0,02.

Para o tipo de embalamento A, B e D os trabalhadores apresentaram um isolamento térmico (clo) de 2,03 \pm 0,25 e para o tipo de embalamento $C$ o valor $1,72 \pm 0,27$. No geral, as peças de vestuário usadas foram cueca, soutien, camisola interior de manga comprida, camisola polar ou camisola comprida de lã, meias, meia calça, calças, luvas e farda.

$\mathrm{Na}$ fig. 8 mostram-se dois gráficos de barras, o do lado esquerdo apresenta os resultados de sintomas que os trabalhadores sentem no posto de trabalho e o do lado direito apresenta os resultados obtidos para a zona corporal onde os trabalhadores sentem o maior desconforto.

A observação do gráfico do lado esquerdo da fig. 8 mostra que cerca de $35 \%$ dos trabalhadores apresentam dor de cabeça, cerca de $30 \%$ fadiga e cerca de $42 \%$ frieiras. Relativamente à zona corporal de desconforto a observação do gráfico do lado direito da fig. 8 mostra que cerca de $35 \%$ referem a cara, cerca de $25 \%$ os pés, cerca de $35 \%$ o tronco e cerca de $75 \%$ as mãos.

\section{Conclusões}

Um ambiente térmico com características termohigrométricas adequadas é fundamental para que qualquer trabalhador se sinta bem no seu local de trabalho, uma vez que contribui para aumentar o seu bem-estar e a sua produtividade (diminuindo a fadiga, por falência de destreza motora). Neste estudo, a queixa de alguns sintomas que os trabalhadores sentem no posto de trabalho foram a dor de cabeça e as frieiras. Relativamente à zona corporal de desconforto os trabalhadores referem a cara, os pés, o tronco e as mãos.
As considerações retiradas das respostas dos trabalhadores sobre a zona corporal de desconforto permitiram ao Departamento de Qualidade estudar estratégias de intervenção nos postos de trabalho. Realça-se a importância de analisar a proteção das mãos, visto esta ser a zona corporal onde os trabalhadores sentem maior desconforto por gerar frieiras e falência de destreza motora. Como na secção de embalamento o ambiente não pode ser aquecido só uma estratégia de cálculo de um melhor isolamento através do vestuário parece ser a via para minimizar o arrefecimento da massa corporal.

Através da análise de dados obtidos foi possível observarse que o ambiente em estudo apresenta condições de desconforto, pois o índice EsConTer apresenta valores muito abaixo do valor considerado termicamente aceitável para conforto, ou seja, inferior a $-0,5$, de acordo com a escala sétima térmica da ISO 7730 (2005). Os dados obtidos revelam que, para os diferentes tipos de embalamento, os valores variaram entre cerca de $-1,2$ e -2,2, indicando sensação térmica de ligeiramente frio a frio, com tendência a muito frio.

Os resultados obtidos e interpretações realizadas pela aplicação dos índices térmicos usados (EsConTer, ITH e PPD) mostraram-se concordantes, podendo concluirse que os índices traduziram de forma expectável o padrão do ambiente térmico nos diferentes tipos de embalamento, evidenciando com clareza os locais e postos de trabalho onde existe maior desconforto térmico e/ou stress térmico. Conclui-se que numa secção de embalamento de peixe ultracongelado o padrão da sensação térmica depende do tipo ou processo de embalamento.

O estudo mostrou que a perceção dos trabalhadores pode ser medida usando uma escala térmica de cores,

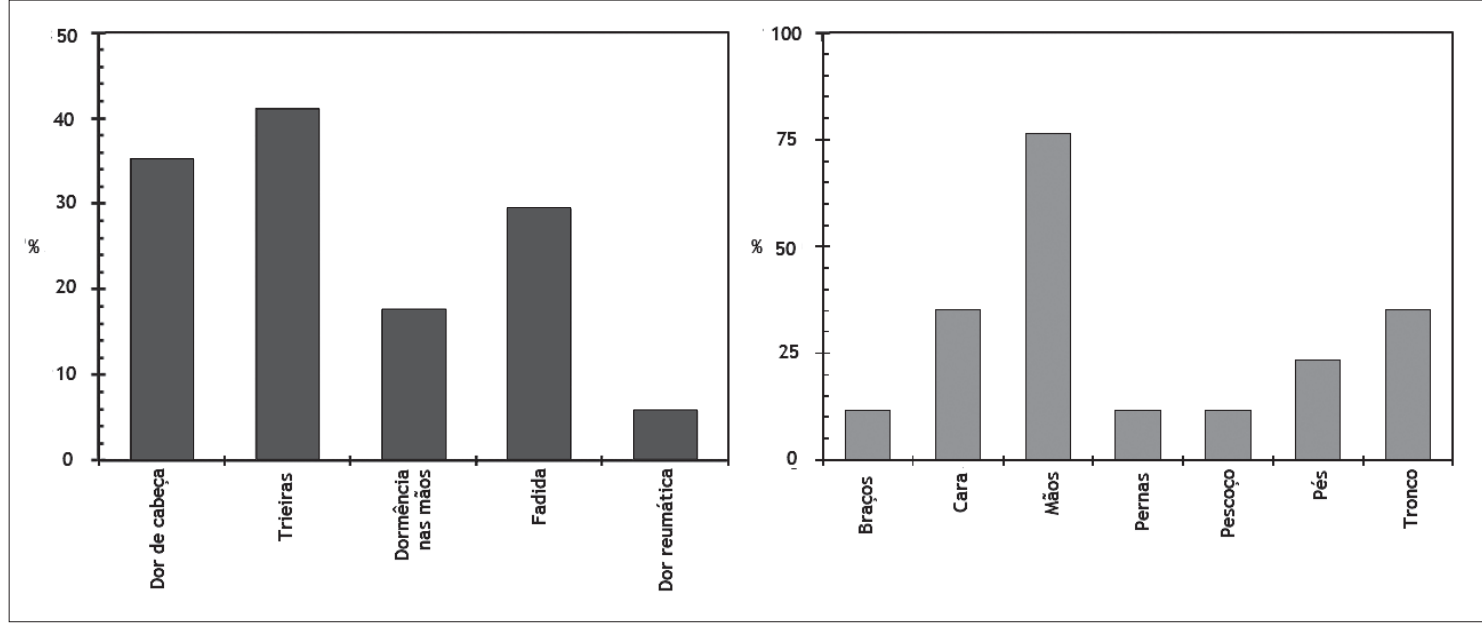

Fig. 8 - Sintomas e zona corporal de desconforto dos trabalhadores no posto de trabalho.

Fig. 8 - Human body part symptoms and discomfort of workers in the workplace. 
numa escala sétima da ASHRAE. O índice EsConTer mostrou ser um bom preditor da sensação térmica que influencia um posto de trabalho e uma ferramenta a ser valorizada pois a sua gama de valores baseia-se na escala sétima de ASHRAE, sendo, portanto de fácil e imediata interpretação. A apresentação dos gráficos de cores permitiu visualizar o padrão do ambiente térmico de uma forma mais intuitiva, mostrando dentro de um espaço as áreas suscetíveis a um maior desconforto térmico. Uma vez que o índice EsConTer prevê uma sensação térmica muito próxima da real dos trabalhadores (usam a mesma escala), sugere-se a sua aplicação em estudos futuros.

A Direção da Qualidade valorizou os resultados obtidos e adotou algumas estratégias de intervenção que passam por reduzir a humidade relativa do ar e por estudar um "clo" para a vestimenta do trabalhador de modo a sentir-se mais confortável, o que diminuirá a fadiga e aumentará a produtividade, criando condições mais favoráveis ao trabalhador.

\section{Referências bibliográficas}

ASHRAE (2004). Standard 55-2004, Thermal environmental conditions for human occupancy. Atlanta.

Costa, E. R. Q., Baptista, J. S., Diogo, M. T., e Magalhães, A. B. (2011). Hot thermal environment and its impact in productivity and accidents. Artigo apresentado em International Symposium on Occupational Safety and Hygiene - SHO 2011.

Dias, A. (2013). Avaliação da perceção da influência do conforto térmico na produtividade (Dissertação de Mestrado em Engenharia Humana). Univ. do Minho, Braga.

Holmér, I., Granberg, P., e Dahlstrom, G. (1999). Ambientes fríos y trabajo com frío. Enciclopedia de Seguridad y Salud en el trabajo. OIT. Cap.42, 32-60.

ISO 7730 (2005). Ergonomics of the thermal environmentAnalytical determination and interpretation of thermal comfort using calculation of the PMV and $P P D$ indices and local thermal comfort criteria. International Organization for Standardization.
Miguel, A. S. (2012). Manual de Higiene e segurança no trabalho. Porto: Porto Editora.

Morgado, M., Talaia, M., e L. Teixeira (2015). A new simplified model for evaluating thermal environment and thermal sensation: An approach to avoid occupational disorders. International Journal of Industrial Ergonomics.

doi:10.1016/j.ergon.2015.11.001

Nieuwolt, S. (1977). Tropical climatology. Wiley.

Parsons, K. C. (1993). Human thermal environments. London; Bristol, PA: Taylor e Francis.

Stoops, J. L. (2004). A possible connection between thermal comfort and health. Lawrence Berkeley National Laboratory.

Talaia, M., Meles, B., e Teixeira, L. (2013). Evaluation of the thermal comfort in workplaces - a study in the metalworking industry. Occupational Safety and Hygiene (pp. 473-477). London: Taylor e Francis Group.

Talaia, M., e Simões, H. (2009). EsConTer: um índice de avaliação de ambiente térmico. In: $V$ Congresso Cubano de Meteorologia. Somet-Cuba, Sociedade de Meteorologia de Cuba; 1612-1626.

Talaia, M., e Rodrigues, F. (2008). Conforto e stress térmico: uma avaliação em ambiente laboral. In Gomes et al. Edição INEGI (Ed.), CLME'2008 // CEM. $8^{\circ}$ Congresso Luso-Moçambicano de engenharia e $2^{\circ}$ Congresso de Engenharia de Moçambique. Maputo. Artigo com15 páginas.

Tavares, I. (2014). Avaliação de ambiente frio e sensação térmica de trabalhadores: estudo de caso numa empresa de bacalhau (Dissertação de grau de mestre em Engenharia e Gestão Industrial). Publicada Universidade de Aveiro.

WMO (1987). World Climate Program Applications, Climate and Human Health. World Meteorological Organization. 